UDC 619:616.98:579.873.21:636.2

doi: $10.36359 /$ scivp.2019-20-2.20

\title{
EFFECT OF ETHANOL PLANT EXTRACTS ON STAPHYLOCOCCUS EPIDERMIDIS, STAPHYLOCOCCUS AUREUS
}

\author{
V. V. Zazharskyi ${ }^{1}$, P. O. Davydenko ${ }^{1}$, O. M. Kulishenko ${ }^{1}$, I. V. Borovik ${ }^{2}$, V. V. Brygadyrenko ${ }^{3}$ \\ ${ }^{1}$ Dnipro State Agrarian and Economic University, Dnipro, Ukraine \\ ${ }^{2}$ Dnipropetrovsk Regional State Laboratory of the State Service of Ukraine for Food Safety \\ and Consumer Protection, Dnipro, Ukraine \\ ${ }^{3}$ Oles Honchar Dnipro National University, Dnipro, Ukraine
}

The emergence of multiresistant strains of Staphylococcus epidermidis, Staphylococcus aureus that are difficult to antibiotics and cause severe lesions of soft tissues, sepsis, and complicated surgical pathology are recognized as the one of problems of current infectious diseases of animals and humans. One of challenges in pharmacognosy is the search for alternative sources of antibacterial substances with an exhaustive resource of antibiotics of fungal origin. The use of raw medicinal plants is quite promising in this regard. The tendency of scientific research of recent decade reveals a promising range of plants of a number of families, which typically contents certain active substances (phytoncides, saponins, alkaloids, glycosides, tannins, essential oils etc.).

The goal of the work was to establish the antibacterial effect of plant infusions on reference cryogenic strains of Staphylococcus epidermidis, Staphylococcus aureus in vitro.

Herbal material of 50 species (seeds, grass, shoots, leaves, compound fruit, peel) obtained at different periods of the growing season was used for investigation. The material was classified, dried, and grounded. Samples of $1 \mathrm{~g}$ were poured with $5 \mathrm{~cm}^{3}$ of $96 \%$ ethanol and were kept it over three weeks in a dry cold place. The obtained alcohol infusion was filtered with sterile multi-layer gauze disc filters. Before the discs were put on the surface of agar with inoculation of the corresponding culture, they were dried in a sterile laminar box under ultraviolet rays. Antibacterial activity of various tinctures was determined by the disk diffusion method in agar with the measurement of the diameter of the growth suppression zone of the culture using a template ruler.

Concerning the above mentioned point, herein, we report the results of the use of tinctures Staphylococcus epidermidis, Staphylococcus aureus in vitro. Obtained data has been systematized, summarized and evaluated.

The paper presents the results of the effectiveness of phytopreparations on Staphylococcus epidermidis, Staphylococcus aureus in vitro. The antibacterial effect of plant tinctures of Cephalotaxus harringtonia, Hedera helix, Geranium sanguineum on cryogenic strains Staphylococcus epidermidis, Staphylococcus aureus. We consider it possible to recommend the investigated extracts of Cephalotaxus harringtonia, Hedera helix, Geranium sanguineum for further research in the fight against polyresistant strains of the above-mentioned microorganisms.

The obtained results give grounds to recommend herbal tinctures to combat multi-resistant strains of Staphylococcus epidermidis, Staphylococcus aureus.

Keywords: ANTIBACTERIAL ACTIVITY, TINCTURE, STAPHYLOCOCCUS EPIDERMIDIS, STAPHYLOCOCCUS AUREUS.

One of the problems of modern veterinary medicine is the antibiotic resistance of Staphylococcus epidermidis, Staphylococcus aureus, which greatly complicates the prevention and control of these infections and reduces the therapeutic efficacy of existing antibacterial and 
antiparasitic agents (Zazharska et al., 2018; Zazharskyi et al., 2018; Boyko \& Brygadyrenko, 2016; Ali et al , 2017; Semeniuc et al., 2017).

According to Dancer et al. (2014), Staphylococcus aureus, including methicillin-resistant strains, is a major cause of nosocomial infections. The rise of specific strains in hospitalized patients and even in the community calls for a better understanding of prevention and control measures.

Research results Karam et al. (2017), suggest that $80 \%$ of S. aureus and $80 \%$ of S. epidrmidis isolates developed Methicillin resistance. The findings of the current work have shown that most of the methicillin-resistant S. aureus (MRSA) and methicillin-resistant S. epidermidis (MRSE) formed a weak biofilm. Results showed that the number of biofilm cells strongly reduced to undetectable limits in the presence of gentamicin.

Vandecandelaere et al. (2017) found that S. epidermidis ET-024 genes encoding resistance to oxacillin, erythromycin and tobramycin were upregulated in dual species biofilms and increased resistance was subsequently confirmed. This indicates that both species in dual species biofilms of $S$. epidermidis and $S$. aureus influence each other's behavior, but additional studies are required to clarify the exact mechanism (s) involved.

Kiranasari et al. (2018) have established that extract of Syzigium aromaticum, Piper betle and Aleurites moluccana were show anti bacterial activity against MRSA (Methicillin-resistant Staphylococcus aureus), Staphylococcus aureus and Staphylococcus epidermidis.

Kirmusaoglu (2017) found the rate of methicillin resistance of biofilm producer Staphylococcus strains are higher than non-biofilm producer Staphylococcus strains, and MRSE strains were more related with biofilm production $(80 \%, 56 / 70)$ than MSSE strains $(64 \%, 138 / 217)$ significantly.

In studies McFadden (2016) explored the role Staphylococcus aureus autolysins play in biofilm formation, pathogenesis and resistance to both cell wall targeting and protein synthesisinhibiting antibiotics. Using a variety of mutant strains in the USA300 background lacking genes encoding autolysins, sortases, histidine-kinase signaling systems, as well as regulatory proteins, the role of these genes in MRSA could be elucidated. The results suggest a variety of negative phenotypes that correlate with the loss of these key autolysins and regulatory genes. Decreases in biofilm formation, antibiotic resistance, and pathogenesis were seen in many of the mutants. This indicates a possible relationship between autolysins and many of the characteristics of pathogenesis in Staphylococcus aureus.

Anitua et al. (2012) got the potential antimicrobial effects of a product (plasma rich in growth factors; PRGF®-Endoret $\left.{ }^{\circledR}\right)$ against both methicillin-sensitive and methicillin-resistant Staphylococcus aureus and Staphylococcus epidermidis. The microbiological activity of PRGFEndoret against both staphylococcal strains was performed by counting the number of the surviving bacterial colonies after incubation at 0,4 and $8 \mathrm{~h}$ with the different formulations.

Antibacterial potency with change of volume was increased in propotion to increase volume and increased on 6 days, but bacteria was increased. Antibacterial potency of Tangpo-san on S. epidermidis wasn't appeared continuouscделав вывод, что Antibacterial potency of Tangpo-san on cultivation of $S$. aureus showed continuous, but on cultivation of S. epidermidis was not showed continuous (Seo, 2007).

The purpose of this article - is to establish the antibacterial effect of in vitro herbal infusions on reference strains Staphylococcus epidermidis, Staphylococcus aureus.

Material and methods. 50 species of plant raw materials (seeds, grass, shoots, leaves, breeding, flax, fruit bodies, skin) of different vegetation periods were harvested in the Dnipropetrovsk botanical garden and the recreational zone of the city of Dnipro

The collected raw materials were sorted and dried in a drying cabinet ML-309 (Poland) at a temperature of $60{ }^{\circ} \mathrm{C}$ for 5-6 days. Subsequently, the raw material was placed in a grain mill grain laboratory LSMK and crushed to a particle size of 0.5-1.0 $\mathrm{mm}$. The resulting vegetable raw material was packed in disposable polyethylene bags with locks and marketed with stickers. $1 \mathrm{~g}$ of appropriate 
crumbled raw material was weighed using laboratory electron analytical grade ESJ-200-4 (USA) and placed in sterile vials of $10 \mathrm{~cm}^{3}$ and poured into $5 \mathrm{~cm}^{3}$ of $96 \%$ ethanol with the appropriate labeling of the vials. Alcoholic tinctures in a ratio of 1: 5 were kept for three weeks by infusion in a dark cool place. After holding, the tincture was filtered through sterile multi-layer gauze filters in sterile vials, which were placed in 50 sterile disks of filter paper $6 \mathrm{~mm}$ in diameter, which were kept in appropriate versions of tinctures for 10 days. Before placing the disks on the agar surface with the sowing of the corresponding culture, they were dried in a sterile laminar box (BMB-II-Laminar-C-1,2 CYTOS (Germany) under ultraviolet rays for 30 minutes.

The antibacterial activity of various plant infusions was determined by the method of disk diffusion in agar. From the daily culture of reference cryogenic strains of Staphylococcus epidermidis, Staphylococcus aureus was prepared according to the standard of turbidity of a bacterial suspension of 0.5 unit density McFarland 1.5 $\times 108$ CFUs (colony forming units), which was determined using densitometry Densimeter II. The obtained charge was transplanted onto a Himedia agar with subsequent cultivation in a thermostat TSO-80/1 (Russia) for 24 hours at $37^{\circ} \mathrm{C}$. On top of the seedings, discs impregnated with appropriate plant infusions were placed on the six-wheel drive in time, as a positive control, placed disks with antibiotics ( 1 disk contains $30 \mu \mathrm{g}$ tetracycline, $5 \mu \mathrm{g}$ ciprofloxacin, $15 \mu \mathrm{g}$ azithromycin).

A day later, the diameter of the growth inhibition zone (GIZ) of the culture was measured using a template ruler to measure the size of the microorganism growth retardation zones (Antibiotic Zone Scale-C, model PW297, India).

Results and discussion. The results of the influence of ethanol extracts on the growth of Staphylococcus epidermidis are given in Table 1.

We determined the moderate sensitivity of the microorganisms Staphylococcus epidermidis to Vitex negundo, Maclura pomifera, Rhus typhina, Koebreteria paniculata, Cephalotaxus harringtonia, Saburumim an angiroides, Aristolochia manshurica, which was equal to the control parameters azithromycin. Intermediate sensitivity was detected in Leptopus chinensis $(\mathrm{P}<0.05)$, Geranium sanguineum $(\mathrm{P}<0.05)$, Celastrus scandens, Clematis flammula $(\mathrm{P}<0.05)$, Chimonanthus praecox $(\mathrm{P}<0.05)$, Rhus trilobata triloboida), GIZ within 14-19 $\mathrm{mm}$. The high sensitivity of the experimental strain was detected by Hedera helix and Mahonia aquifolium spp. (within 21-27 mm). In addition, the GIZ to Hedera helix is higher than control (tetracycline and azithromycin) at 2.2 and $11.6 \mathrm{~mm}$ respectively. Mahonia aquifolium spp. Has GIZ above azithromycin $6.8 \mathrm{~mm}(\mathrm{P}<0.05)$.

Analyzing the effectiveness of the effect of the experimental drugs on Staphylococcus aureus (Table 2), we determined the fluctuations of the growth inhibition zone of more than $10 \mathrm{~mm}$ with the use of Juníperus sabína, Styphnolobium japonicum, Cotinus coggygria, Ginkgo biloba, Quercus castaneifolia, Ptelea trifoliata, Toxicodendron orientale (GIZ 10-13 mm), which in 2 and more times below control (tetracycline, ciprofloxacin, azithromycin). Intermediate sensitivity is defined for Clematis flammula, Celastrus scandens, Rhus trilobata (triloboida), which is 4-10 mm insignificantly below control.

We detected a highly sensitive antibacterial effect on the Staphylococcus aureus strain under the action of Cephalotaxus harringtonia, Hedera helix, Geranium sanguineum, and GIZ ranged from 21 to $28 \mathrm{~mm}$. Moreover, if the effect of Cephalotaxus harringtonia at the control level (ciprofloxacin and azithromycin), then Hedera helix, Geranium sanguineum exceeded the control: by $2.1 ; 1.0 \mathrm{~mm}$ and $4.2 ; 1.0 \mathrm{~mm}$ respectively. The highest antibacterial effect is obtained from tetracycline (GIZ within 26-29 mm). 
Effect of ethanolic extracts on growth of Staphylococcus epidermidis, $(M \pm m), n=12$

\begin{tabular}{|c|c|c|c|c|c|}
\hline \multirow[b]{2}{*}{ № } & \multirow{2}{*}{ The name of the plant } & \multirow{2}{*}{$\begin{array}{c}\text { Growth } \\
\text { inhibition } \\
\text { zone, } \mathrm{mm}\end{array}$} & \multicolumn{3}{|c|}{ Reference, $\mathrm{mm}$} \\
\hline & & & Tetracycline & Ciprofloxacin & Azithromycin \\
\hline 1 & Vitex negundo & $10,5 \pm 2,13$ & $26,5 \pm 3,44$ & $27,6 \pm 4,54$ & $11,3 \pm 1,89$ \\
\hline 2 & Genista tanaitica & 0 & $28,7 \pm 3,56$ & $28,8 \pm 3,12$ & $13,6 \pm 1,67$ \\
\hline 3 & Juníperus sabína & 0 & $24,6 \pm 2,45$ & $29,7 \pm 3,25$ & $10,8 \pm 1,19$ \\
\hline 4 & Leptopus chinensis & $18,7 \pm 1,78^{*}$ & $24,9 \pm 2,45$ & $26,4 \pm 2,56$ & $12,9 \pm 1,67^{*}$ \\
\hline 5 & Chamaecyparis lawsoniana & 0 & $25,4 \pm 3,12$ & $28,9 \pm 4,13$ & $13,1 \pm 1,78$ \\
\hline 6 & Pseudotsuga menziesii & 0 & $27,1 \pm 2,67$ & $29,8 \pm 3,24$ & $10,3 \pm 1,34$ \\
\hline 7 & Styphnolobium japonicum & 0 & $28,2 \pm 3,12$ & $27,6 \pm 2,87$ & $12,6 \pm 1,78$ \\
\hline 8 & Artemisia absinthium & $2,3 \pm 0,67$ & $24,1 \pm 1,45$ & $26,9 \pm 2,67$ & $11,6 \pm 1,98$ \\
\hline 9 & Maclura pomifera & $10,9 \pm 1,12$ & $23,6 \pm 2,34$ & $27,7 \pm 3,21$ & $10,7 \pm 1,56$ \\
\hline 10 & Koebreteria paniculata & $11,3 \pm 1,45$ & $28,5 \pm 3,42$ & $28,8 \pm 2,87$ & $12,7 \pm 1,44$ \\
\hline 11 & Phellodendron amurense & $2,6 \pm 0,45$ & $24,7 \pm 2,56$ & $27,6 \pm 3,12$ & $13,6 \pm 1,32$ \\
\hline 12 & Vitex agnus castus & $4,4 \pm 0,78$ & $26,4 \pm 2,58$ & $26,3 \pm 2,77$ & $10,4 \pm 0,87$ \\
\hline 13 & Rhus typhina & $10,7 \pm 1,22$ & $28,5 \pm 4,32$ & $28,9 \pm 3,67$ & $14,3 \pm 1,55$ \\
\hline 14 & Aralia elata & 0 & $24,4 \pm 2,43$ & $29,2 \pm 3,34$ & $12,6 \pm 1,78$ \\
\hline 15 & Cotinus coggygria & $11,9 \pm 1,54$ & $26,8 \pm 2,54$ & $26,7 \pm 3,21$ & $11,1 \pm 1,67$ \\
\hline 16 & Cephalotaxus harringtonia & $13,4 \pm 1,45$ & $27,8 \pm 3,17$ & $29,7 \pm 2,89$ & $13,9 \pm 1,15$ \\
\hline 17 & Polygonatum multiflorum & $8,6 \pm 1,34$ & $25,7 \pm 3,45$ & $26,9 \pm 2,98$ & $12,7 \pm 1,56$ \\
\hline 18 & Dictamnus alba & $8,9 \pm 1,56$ & $24,6 \pm 2,56$ & $28,8 \pm 3,54$ & $13,8 \pm 1,78$ \\
\hline 19 & Amygdalus communis (prensculi) & $8,5 \pm 2,13$ & $28,9 \pm 3,54$ & $27,6 \pm 3,56$ & $12,1 \pm 0,87$ \\
\hline 20 & Hedera helix & $26,3 \pm 2,15$ & $24,1 \pm 3,12$ & $28,4 \pm 2,78$ & $14,7 \pm 1,46$ \\
\hline 21 & Eucommia ulmoides & 0 & $26,7 \pm 2,32$ & $26,8 \pm 1,99$ & $13,7 \pm 0,87$ \\
\hline 22 & Geranium sanguineum & $18,4 \pm 1,45^{*}$ & $27,4 \pm 2,76$ & $29,7 \pm 3,78$ & $14,2 \pm 1,38^{*}$ \\
\hline 23 & Kalicopa bodimerium & $8,3 \pm 1,13$ & $26,9 \pm 2,78$ & $26,5 \pm 2,67$ & $13,7 \pm 2,11$ \\
\hline 24 & Salvia officinalis & $6,2 \pm 0,88$ & $26,4 \pm 2,55$ & $29,8 \pm 3,76$ & $11,7 \pm 1,66$ \\
\hline 25 & Chimonanthus praecox & $18,7 \pm 1,84^{*}$ & $26,5 \pm 3,67$ & $28,4 \pm 4,23$ & $13,7 \pm 1,49^{*}$ \\
\hline 26 & Nepeta mussinii & 0 & $24,8 \pm 2,56$ & $27,5 \pm 3,24$ & $11,8 \pm 0,98$ \\
\hline 27 & Tamarix elongata & $8,7 \pm 1,77$ & $23,8 \pm 2,78$ & $26,9 \pm 2,67$ & $10,4 \pm 1,65$ \\
\hline 28 & Catalpa fargesii & 0 & $25,7 \pm 3,32$ & $27,5 \pm 4,12$ & $14,3 \pm 1,88$ \\
\hline 29 & Wisteria sinensis & 0 & $24,9 \pm 2,76$ & $28,7 \pm 3,12$ & $12,8 \pm 1,15$ \\
\hline 30 & Ailanthus altissima & $1,2 \pm 0,22$ & $26,5 \pm 2,77$ & $27,7 \pm 3,65$ & $11,7 \pm 1,69$ \\
\hline 31 & Saburumim anagiroides & $10,3 \pm 1,57$ & $25,2 \pm 2,97$ & $26,2 \pm 3,56$ & $10,5 \pm 1,78$ \\
\hline 32 & Securigera varia & 0 & $27,2 \pm 3,42$ & $29,8 \pm 4,12$ & $12,3 \pm 2, ! 8$ \\
\hline 33 & Potensisus tricopidata & 0 & $26,7 \pm 2,44$ & $28,8 \pm 3,19$ & $14,9 \pm 1,23$ \\
\hline 34 & Magnolia kobus & 0 & $24,8 \pm 1,89$ & $27,5 \pm 2,16$ & $12,3 \pm 1,89$ \\
\hline 35 & Berberis vulgaris & 0 & $24,4 \pm 2,14$ & $26,7 \pm 2,32$ & $12,7 \pm 1,98$ \\
\hline 36 & Clematis flammula & $18,7 \pm 1,77^{*}$ & $26,6 \pm 2,56$ & $29,4 \pm 3,78$ & $11,6 \pm 2,19^{*}$ \\
\hline 37 & Aristolochia manshurica & $12,8 \pm 2,44$ & $24,1 \pm 3,34$ & $28,3 \pm 4,15$ & $10,7 \pm 2,67$ \\
\hline 38 & Celastrus scandens & $15,3 \pm 1,78$ & $27,8 \pm 3,21$ & $27,4 \pm 2,67$ & $12,6 \pm 1,67$ \\
\hline 39 & Mahonia aquifolium spp. & $21,6 \pm 2,34^{*}$ & $23,6 \pm 1,78$ & $25,6 \pm 3,11$ & $14,8 \pm 1,78^{*}$ \\
\hline 40 & Quercus petrariberica & 0 & $24,5 \pm 2,34$ & $29,5 \pm 3,21$ & $12,5 \pm 1,87$ \\
\hline 41 & Ginkgo biloba & $8,7 \pm 0,76$ & $28,7 \pm 3,31$ & $28,3 \pm 2,89$ & $11,8 \pm 1,13$ \\
\hline 42 & Colchicum autumnale & $8,3 \pm 0,88$ & $23,8 \pm 2,44$ & $29,8 \pm 4,33$ & $12,7 \pm 2,11$ \\
\hline 43 & Quercus castaneifolia & $8,9 \pm 1,13$ & $26,3 \pm 2,43$ & $26,5 \pm 2,87$ & $14,8 \pm 1,89$ \\
\hline 44 & Rhus trilobata (triloboida) & $14,4 \pm 0,78$ & $25,8 \pm 2,49$ & $28,4 \pm 1,98$ & $12,9 \pm 1,77$ \\
\hline 45 & Prunus laurocerasus & $2,3 \pm 0,76$ & $24,9 \pm 2,12$ & $29,1 \pm 3,12$ & $13,8 \pm 2,32$ \\
\hline 46 & Ptelea trifoliata & $4,6 \pm 0,87$ & $23,6 \pm 2,33$ & $25,2 \pm 2,11$ & $11,7 \pm 1,32$ \\
\hline 47 & Toxicodendron orientale & 0 & $26,7 \pm 3,54$ & $29,5 \pm 4,11$ & $13,8 \pm 1,67$ \\
\hline 48 & Liriodendrom talipifero & 0 & $27,6 \pm 2,76$ & $28,7 \pm 2,67$ & $14,7 \pm 0,87$ \\
\hline 49 & Campsis radicans & 0 & $28,7 \pm 3,45$ & $29,6 \pm 3,21$ & $13,5 \pm 2,11$ \\
\hline 50 & Pterídium aquilínum & 0 & $25,5 \pm 2,15$ & $28,4 \pm 2,56$ & $12,8 \pm 1,76$ \\
\hline
\end{tabular}


Effect of ethanolic extracts on growth of Staphylococcus aureus, $(M \pm m), n=12$

\begin{tabular}{|c|c|c|c|c|c|}
\hline \multirow[b]{2}{*}{ № } & \multirow[b]{2}{*}{ The name of the plant } & \multirow{2}{*}{$\begin{array}{c}\text { Growth } \\
\text { inhibition } \\
\text { zone, mm }\end{array}$} & \multicolumn{3}{|c|}{ Reference, $\mathrm{mm}$} \\
\hline & & & Tetracycline & Ciprofloxacin & Azithromycin \\
\hline 1 & Vitex negundo & 0 & $27,4 \pm 2,19$ & $20,9 \pm 2,98$ & $24,1 \pm 2,54$ \\
\hline 2 & Genista tanaitica & $1,3 \pm 0,11$ & $25,7 \pm 2,98$ & $22,8 \pm 2,97$ & $22,3 \pm 2,39$ \\
\hline 3 & Juníperus sabína & $11,5 \pm 0,64$ & $24,6 \pm 2,67$ & $21,7 \pm 2,68$ & $21,6 \pm 2,45$ \\
\hline 4 & Leptopus chinensis & $2,6 \pm 0,21$ & $27,9 \pm 2,66$ & $19,4 \pm 2,11$ & $22,5 \pm 1,77$ \\
\hline 5 & Chamaecyparis lawsoniana & $4,4 \pm 0,32$ & $28,4 \pm 2,14$ & $18,9 \pm 2,15$ & $23,2 \pm 2,39$ \\
\hline 6 & Pseudotsuga menziesii & $4,1 \pm 0,33$ & $29,1 \pm 2,66$ & $19,8 \pm 2,93$ & $24,1 \pm 2,48$ \\
\hline 7 & Styphnolobium japonicum & $10,7 \pm 0,89$ & $25,2 \pm 2,76$ & $20,6 \pm 2,32$ & $22,6 \pm 2,34$ \\
\hline 8 & Artemisia absinthium & $4,5 \pm 0,43$ & $26,1 \pm 2,69$ & $20,9 \pm 2,68$ & $20,9 \pm 2,25$ \\
\hline 9 & Maclura pomifera & $1,7 \pm 0,31$ & $27,6 \pm 2,19$ & $19,7 \pm 2,67$ & $20,9 \pm 1,88$ \\
\hline 10 & Koebreteria paniculata & $3,2 \pm 0,24$ & $26,5 \pm 2,33$ & $21,8 \pm 2,76$ & $23,1 \pm 2,35$ \\
\hline 11 & Phellodendron amurense & $4,8 \pm 0,43$ & $26,7 \pm 2,79$ & $21,6 \pm 2,15$ & $25,6 \pm 2,32$ \\
\hline 12 & Vitex agnus castus & $6,5 \pm 0,42$ & $25,4 \pm 2,61$ & $19,3 \pm 2,04$ & $24,1 \pm 2,27$ \\
\hline 13 & Rhus typhina & $8,3 \pm 0,46$ & $24,5 \pm 2,36$ & $22,9 \pm 2,13$ & $22,5 \pm 2,78$ \\
\hline 14 & Aralia elata & $9,7 \pm 0,78$ & $29,4 \pm 2,16$ & $19,2 \pm 2,79$ & $23,4 \pm 2,77$ \\
\hline 15 & Cotinus coggygria & $13,3 \pm 1,12$ & $29,8 \pm 2,11$ & $18,7 \pm 2,78$ & $25,3 \pm 2,67$ \\
\hline 16 & Cephalotaxus harringtonia & $21,2 \pm 2,41$ & $28,8 \pm 2.33$ & $21,7 \pm 2,16$ & $21,8 \pm 2,56$ \\
\hline 17 & Polygonatum multiflorum & $9,9 \pm 0,91$ & $27,7 \pm 2,79$ & $20,9 \pm 2,36$ & $24,9 \pm 2,78$ \\
\hline 18 & Dictamnus alba & $2,1 \pm 0,26$ & $26,6 \pm 2,51$ & $21,8 \pm 2,52$ & $25,8 \pm 2,67$ \\
\hline 19 & Amygdalus communis (prensculi) & $3,8 \pm 0,32$ & $25,9 \pm 2,61$ & $20,6 \pm 2,21$ & $22,6 \pm 2,67$ \\
\hline 20 & Hedera helix & $23,5 \pm 2,78$ & $26,1 \pm 2,21$ & $21,4 \pm 2,41$ & $22,7 \pm 2,21$ \\
\hline 21 & Eucommia ulmoides & $1,3 \pm 0,11$ & $27,7 \pm 2,51$ & $22,8 \pm 2,09$ & $24,6 \pm 2,67$ \\
\hline 22 & Geranium sanguineum & $25,9 \pm 3,12$ & $29,4 \pm 2,57$ & $21,7 \pm 2,12$ & $24,4 \pm 2,78$ \\
\hline 23 & Kalicopa bodimerium & $3,5 \pm 0,12$ & $29,9 \pm 2,61$ & $19,5 \pm 2,27$ & $25,9 \pm 3,41$ \\
\hline 24 & Salvia officinalis & $2,4 \pm 0,23$ & $28,4 \pm 2,44$ & $18,8 \pm 2,98$ & $22,4 \pm 2,13$ \\
\hline 25 & Chimonanthus praecox & $5,2 \pm 0,24$ & $27,5 \pm 2,61$ & $19,4 \pm 2,29$ & $23,5 \pm 2,21$ \\
\hline 26 & Nepeta mussinii & 0 & $26,8 \pm 2,88$ & $20,5 \pm 2,89$ & $22,5 \pm 2,19$ \\
\hline 27 & Tamarix elongata & $4,8 \pm 0,42$ & $27,8 \pm 2,87$ & $21,9 \pm 2,22$ & $25,6 \pm 2,31$ \\
\hline 28 & Catalpa fargesii & $4,2 \pm 0,34$ & $26,7 \pm 2,46$ & $20,5 \pm 2,78$ & $22,4 \pm 2,11$ \\
\hline 29 & Wisteria sinensis & 0 & $27,9 \pm 2,12$ & $21,7 \pm 2.51$ & $23,8 \pm 1.97$ \\
\hline 30 & Ailanthus altissima & 0 & $28,5 \pm 2,41$ & $19,7 \pm 2,32$ & $22,1 \pm 2,14$ \\
\hline 31 & Saburumim anagiroides & 0 & $27,2 \pm 2,78$ & $18,2 \pm 2,76$ & $23,8 \pm 2,41$ \\
\hline 32 & Securigera varia & 0 & $26,2 \pm 2,69$ & $19,8 \pm 2,32$ & $22,4 \pm 2,71$ \\
\hline 33 & Potensisus tricopidata & 0 & $28,7 \pm 2,54$ & $20,8 \pm 2,21$ & $24,5 \pm 2,31$ \\
\hline 34 & Magnolia kobus & 0 & $26,8 \pm 2,61$ & $20,5 \pm 2,41$ & $24,6 \pm 2,13$ \\
\hline 35 & Berberis vulgaris & $1,8 \pm 0,11$ & $27,4 \pm 2,32$ & $19,7 \pm 2,62$ & $22,4 \pm 2,31$ \\
\hline 36 & Clematis flammula & $16,4 \pm 1,34$ & $25,6 \pm 2,23$ & $19,4 \pm 2,77$ & $24,8 \pm 2,74$ \\
\hline 37 & Aristolochia manshurica & $1,9 \pm 0,18$ & $27,1 \pm 2,77$ & $18,3 \pm 2,11$ & $24,4 \pm 2,31$ \\
\hline 38 & Celastrus scandens & $14,4 \pm 1,54$ & $28,8 \pm 2,98$ & $21,4 \pm 2,41$ & $24,8 \pm 2,53$ \\
\hline 39 & Mahonia aquifolium spp. & $2,8 \pm 0,19$ & $26,6 \pm 2,41$ & $22,6 \pm 2,12$ & $22,6 \pm 2,31$ \\
\hline 40 & Quercus petrariberica & 0 & $26,5 \pm 2,67$ & $22,5 \pm 2,03$ & $23,2 \pm 2,59$ \\
\hline 41 & Ginkgo biloba & $10,8 \pm 0,89$ & $25,7 \pm 2,76$ & $21,3 \pm 2,51$ & $20,9 \pm 2,46$ \\
\hline 42 & Colchicum autumnale & $8,5 \pm 0,76$ & $27,8 \pm 2,89$ & $18,8 \pm 2,78$ & $22,4 \pm 2,77$ \\
\hline 43 & Quercus castaneifolia & $11,4 \pm 1,43$ & $27,3 \pm 2,71$ & $21,5 \pm 2,61$ & $20,6 \pm 2,77$ \\
\hline 44 & Rhus trilobata (triloboida) & $15,8 \pm 1,29$ & $26,8 \pm 2,24$ & $19,4 \pm 2,76$ & $22,8 \pm 2,11$ \\
\hline 45 & Prunus laurocerasus & $7,5 \pm 0,88$ & $27,9 \pm 2,76$ & $20,1 \pm 2,78$ & $22,6 \pm 2,75$ \\
\hline 46 & Ptelea trifoliata & $10,3 \pm 0,92$ & $28,6 \pm 2,59$ & $21,2 \pm 2,21$ & $23,3 \pm 2,14$ \\
\hline 47 & Toxicodendron orientale & $10,8 \pm 0,87$ & $26,7 \pm 2,76$ & $19,5 \pm 2,08$ & $21,8 \pm 2,31$ \\
\hline 48 & Liriodendrom talipifero & $1,3 \pm 0,19$ & $29,6 \pm 2,34$ & $18,7 \pm 2,64$ & $21,5 \pm 2,11$ \\
\hline 49 & Campsis radicans & 0 & $27,7 \pm 2,21$ & $19,6 \pm 2,42$ & $22,7 \pm 2,41$ \\
\hline 50 & Pterídium aquilínum & $2,7 \pm 0,18$ & $27,2 \pm 2,44$ & $21,4 \pm 2,21$ & $21,9 \pm 1,56$ \\
\hline
\end{tabular}




\title{
C O N C L US I O N
}

In vitro experiment revealed a positive antibacterial effect from the use of extracts of Cephalotaxus harringtonia, Hedera helix, Geranium sanguineum on cryogenic strains Staphylococcus epidermidis, Staphylococcus aureus. We consider it possible to recommend the investigated extracts of Cephalotaxus harringtonia, Hedera helix, Geranium sanguineum for further research in the fight against polyresistant strains of the above-mentioned microorganisms.

Conflicts of interest. The authors declare that there is no conflict of interest. The authors alone are responsible for the content of the paper.

\section{ВПЛИВ ЕТАНОЛЬНИХ РОСЛИИНИХ ЕКСТРАКТІВ НА STAPHYLOCOCCUS EPIDERMIDIS, STAPHYLOCOCCUS AUREUS}

\author{
В. В. Зажарський, канд. вет. наук, дочент, \\ П. О. Давиденко ${ }^{1}$, канд. вет. наук, доиент, \\ О. М. Кулішенко ${ }^{1}$ канд. вет. наук, доцент, \\ I. В. Боровік ${ }^{2}$ зав. бактеріологічного відділу, \\ В. В. Бригадиренко ${ }^{3}$ канд. біол. наук, доцент \\ ${ }^{1}$ Дніпровський державний аграрно-економічний університет \\ вул. Сергія Єфремова, 25, м. Дніпро, 49600, Україна \\ ${ }^{2}$ Дніпропетровська регіональна державна лабораторія Держпродспоживслужби України \\ пр. Олександра Поля, 48, м. Дніпро, 49054, Україна \\ ${ }^{3}$ Дніпровський національний університет імені Олеся Гончара \\ пр. Гагаріна, 72, м. Дніпро, 49000, Україна
}

\section{А Н О Т А Ц І Я}

Останнім часом все частіше з'являються повідомлення про потенційну можливість пошуку ефективних антибактеріальних речовин в рослинних екстрактах в зв'язку з поширенням полірезистентних до антибіотиків бактеріальних штамів, які важко піддаються лікуванню.

Однією з проблем у фармакогнозії є пошук альтернативних джерел антибактеріальних речовин $з$ вичерпним ресурсом антибіотиків грибного походження. Використання етанольних екстрактів лікарських рослин є досить перспективним у цьому відношенні. Тенденція наукових досліджень останнього десятиліття розкриває багатообіцяючий асортимент рослин ряду родин, які зазвичай містять певні активні речовини (фітонциди, сапоніни, алкалоїди, глікозиди, дубильні речовини, ефірні масла тощо).

Метою роботи було встановлення антибактеріального ефекту етанольних екстрактів рослин на штами Staphylococcus epidermidis, Staphylococcus aureus in vitro.

Для дослідження використовували рослинний матеріал 50 видів (насіння, трава, пагони, листя), отримані в різний час вегетаційного періоду. Матеріал був класифікований і висушений. Зразки по 1 г виливали 5 см³ 96\% етанолу і витримували протягом трьох тижнів в сухому холодному місці. Отриманий спиртовий настій фільтрували стерильними багатошаровими марлевими дисковими фільтрами. Перед тим, як диски були поміщені на поверхню агару з інокуляцією відповідної культури, їх сушили в стерильному ламінарному ящику під ультрафіолетовими променями. Антибактеріальну активність різних настоїв визначали методом дискової дифузії в агарі 3 вимірюванням діаметра зони пригнічення росту культури з використанням шаблону лінійки. Отримані дані систематизовані, узагальнені та оцінені.

У статті представлені результати ефективності фітопрепаратів на Staphylococcus epidermidis, Staphylococcus aureus in vitro. Антибактеріальна дія рослинних настоянок Cephalotaxus harringtonia, 
Hedera helix, Geranium sanguineum на кріогенні штами Staphylococcus epidermidis, Staphylococcus aureus. Ми вважаємо за можливе рекомендувати досліджені екстракти Головчастого тису Гаррингтону, Плюща звичайного, Герань криваво-червону для подальших досліджень у боротьбі 3 полірезистентними штамами вищезгаданих мікроорганізмів.

Отримані результати дають підстави рекомендувати трав'яні настоянки для боротьби 3 мультирезистентними штамами Staphylococcus epidermidis, Staphylococcus aureus.

Ключові слова: АНТИБАКТЕРІАЛЬНА АКТИВНІСТЬ, ЕТАНОЛЬНІ ЕКСТРАКТИ, STAPHYLOCOCCUS EPIDERMIDIS, STAPHYLOCOCCUS AUREUS.

\section{ВЛИЯНИЕ ЭТАНОЛЬНЫХ РАСТИТЕЛЬНЫХ ЭКСТРАКТОВ НА STAPHYLOCOCCUS EPIDERMIDIS, STAPHYLOCOCCUS AUREUS}

В. В. Зажарский', П. А. Давыденко ${ }^{1}$, О. Н. Кулишенко ${ }^{1}$, И. В. Боровик², В. В. Бригадиренко

${ }^{1}$ Днепровский государственный аграрно-экономический университет ул. Сергея Ефремова, 25, г. Днепр, 49600, Украина

${ }^{2}$ Днепропетровская региональная государственная лаборатория Государственной службы Украины по вопросам безопасности пищевых продуктов и защиты потребителей пр. Александра Поля, 48, г. Днепр, 49054, Украина

${ }^{3}$ Днепровский национальный университет имени Олеся Гончара пр. Гагарина, 72, г. Днепр, 49000, Украина

\section{А ННО Т АЦИЯ}

В последнее время все чаще появляются сообщения о потенциальной возможности поиска эффективных антибактериальных веществ в растительных экстрактах в связи с распространением полирезистентных к антибиотикам бактериальных штаммов, которые трудно поддаются лечению.

Одной из проблем в фармакогнозии является поиск альтернативных источников антибактериальных веществ с исчерпывающим ресурсом антибиотиков грибного происхождения. Использование этанольных экстрактов лекарственных растений является перспективным в этом отношении. Тенденция научных исследований последнего десятилетия раскрывает многообещающий ассортимент растений ряда семей, которые обычно содержат определенные активные вещества (фитонциды, сапонины, алкалоиды, гликозиды, дубильные вещества, эфирные масла и т.п.).

Целью работы было установление антибактериального эффекта этанольных экстрактов растений на штаммы Staphylococcus epidermidis, Staphylococcus aureus in vitro. Для исследования использовали растительный материал 50 видов (семена, трава, побеги, листья), полученные в разное время вегетационного периода. Материал был классифицирован и высушен. Образцы по 1 г выливали 5 см3 96 \% этанола и выдерживали в течение трех недель в сухом холодном месте. Полученный спиртовой настой фильтровали стерильными многослойными марлевыми дисковыми фильтрами. Перед тем, как диски были помещены на поверхность агара с инокуляцией соответствующей культуры, их сушили в стерильном ламинарном ящике под ультрафиолетовыми лучами. Антибактериальную активность различных настоев определяли методом дисковой диффузии в агаре с измерением диаметра зоны подавления роста культуры с использованием шаблона линейки. Полученные данные систематизированы, обобщены и оценены.

В статье представлены результаты эффективности фитопрепаратов на Staphylococcus epidermidis, Staphylococcus aureus in vitro. Антибактериальное действие растительных настоек Cephalotaxus harringtonia, Hedera helix, Geranium sanguineum на криогенные штаммы Staphylococcus epidermidis, Staphylococcus aureus. Мы считаем возможным рекомендовать исследованные экстракты Головчатотисса Харрингтона, Плюща обыкновенного, Герани кроваво-красной для 
дальнейших исследований в борьбе с полирезистентными штаммами вышеупомянутых микроорганизмов.

Полученные результаты дают основания рекомендовать травяные настойки для борьбы с мультирезистентными штаммами Staphylococcus epidermidis, Staphylococcus aureus.

Ключевые слова: АНТИБАКТЕРИАЛЬНА АКТИВНОСТЬ, ЭТАНОЛЬНЫЕ ЭKCTPAKTЫ, STAPHYLOCOCCUS EPIDERMIDIS, STAPHYLOCOCCUS AUREUS.

\section{References}

1. Anitua E, Alonso R, Girbau C, Aguirre JJ, Muruzabal F, Orive G. Antibacterial effect of plasma rich in growth factors (PRGF®-Endoret ${ }^{\circledR}$ ) against Staphylococcus aureus and Staphylococcus epidermidis strains. Clinical and Experimental Dermatology [Internet]. Wiley; 2012 Feb 14;37(6):652-7. Available from: http://dx.doi.org/10.1111/j.1365-2230.2011.04303.x

2. Dancer SJ. Staphylococcus aureus antibiotic resistance. Clinical Insights: Staphylococcus aureus Antibiotic Resistance [Internet]. Future Medicine Ltd; 2014 Jul;2-5. Available from: http://dx.doi.org/10.2217/ebo.13.716

3. Zazharska N, Boyko O, Brygadyrenko V. Influence of diet on the productivity and characteristics of goat milk. Indian J Anim Res. 2018;52(5):711-7. doi:10.18805/ijar.v0iOF.6826

4. Zazharskyi VV, Davydenko P, Kulishenko O, Chumak V, Kryvaya A, Biben IA, Tishkina NM, Borovik I, Boyko OO, Brygadyrenko VV. Bactericidal, protistocidal and nematodicidal properties of mixtures of alkyldimethylbenzyl ammonium chloride, didecyldimethyl ammonium chloride, glutaraldehyde and formaldehyde. Regul. Mech Biosyst. 2018;9(4):540-5. doi:10.15421/021881

5. Karam N.J., Fahad Al-Mathkhury H.J. Staphylococcus epidermidis Prevails Staphylococcus aureus in Multispecies Biofilm under Gentamicin Stress. International Journal of Science and Research (IJSR) [Internet]. International Journal of Science and Research; 2017 Jul 5;6(7):528-39. Available from: http://dx.doi.org/10.21275/20061703

6. Kiranasari A, Bonita A, Melina E, Winston K, Baht N, Sutandi N, et al. Antibacterial Activity of Several Indonesian Endemic Plants against Staphylococcus epidermidis, Staphylococcus aureus and Methicillin-resistant Staphylococcus aureus. Proceedings of BROMO Conference [Internet]. SCITEPRESS - Science and Technology Publications; 2018; Available from: http://dx.doi.org/10.5220/0008359501780182

7. Kirmusaoglu S. The Correlation of The Biofilm Production with Methicillin Resistance in Staphylococcus aureus and Staphylococcus epidermidis. PONTE International Scientific Researchs Journal [Internet]. Ponte Academic Journal; 2017;73(4). Available from: http://dx.doi.org/10.21506/j.ponte.2017.4.17

8. McFadden SA. Role of Autolysins in Biofilm Formation, Pathogenesis and Antibiotic Resistance in Staphylococcus aureus. Illinois State University; Available from: http://dx.doi.org/10.30707/etd2016.mcfadden.s

9. Vandecandelaere I, Van Nieuwerburgh F, Deforce D, Coenye T. Metabolic activity, urease production, antibiotic resistance and virulence in dual species biofilms of Staphylococcus epidermidis and Staphylococcus aureus. Rohde H, editor. PLOS ONE [Internet]. Public Library of Science (PLoS); $2017 \quad$ Mar 6;12(3):e0172700. Available from: http://dx.doi.org/10.1371/journal.pone.0172700

10. Seo H-S. The Experimental Study on the continuous Anti-bacterial Potency of Tangposan on Cultivation of Staphylococcus species(S. aureus, S. epidermidis). Journal of Korean Institute of Herbal Acupuncture [Internet]. Korean Pharmacopuncture Institute; 2007 Jun 30;10(2):67-71. Available from: http://dx.doi.org/10.3831/kpi.2007.10.2.067

Рецензент - П. М. Скляров, д. вет. н., професор кафедри хірургії та акушерства Дніпровського державного аграрно-економічного університету. 